\title{
Impact of DC Breaker Systems on Multi- Terminal VSC-HVDC Stability
}

\author{
Wenyuan Wang, Student Member, IEEE, Mike Barnes, Senior Member, IEEE, Ognjen Marjanovic, \\ Member, IEEE, and Oliver Cwikowski, Student Member, IEEE
}

\begin{abstract}
The use of VSC-HVDC grids for offshore wind farm integration will require the use of dc breaker systems and they, at present, will require dc reactors to limit the rate of rise of fault current. The introduction of large dc reactors throughout a VSCHVDC system can have significant impact on its stable operation and will require additional control. This paper analyses this problem and proposes a PSS-like control (DCPSS) to aid de grid stability and cope with this effect. A generalized analytical model for studies on de voltage control is presented. Key stability and transient performance issues caused by the use of the dc reactors in a multi-terminal system, are investigated by analyzing poles, zeros and frequency responses of both open-loop and closed-loop models. Design and location identification methods for the DCPSS are provided. Excellent damping enhancement is achieved by this controller. The analytical studies and time-domain simulations in this paper are performed based on two VSC-HVDC models.
\end{abstract}

Index Terms-VSC-HVDC, multi-terminal, stability, DC breaker, droop control.

\section{INTRODUCTION}

$\mathrm{T}$ HE use of VSC-HVDC for offshore wind-farm interconnection typically becomes cost-effective after 60 to $100 \mathrm{~km}$. At present point-to-point connections are used one wind farm connection to shore via one dedicated link, with power ratings in the range of 500 to $1000 \mathrm{MW}$. As the number of such links grows, and wind-farm sites reach multi-GW power ratings, the use of multi-terminal VSC-HVDC (MTDC), or even HVDC grids, becomes attractive to improve reliability, security and potentially to reduce capital cost.

At present, fault clearance for point-to-point systems is undertaken by ac side breakers. For large dc grids, this will be impractical since the entire dc grid would need to be deenergised. The disruption caused by such an event would most likely be prohibitive. HVDC circuit breakers (DCCB) to isolate faulted lines individually would be needed, such as the design shown in Fig. 1. Thus substantial research has been undertaken by major manufacturers in developing dc breakers, and very good progress is being made in developing full-scale commercial devices $[1,2]$.

All such devices to date however rely on a relatively large $\mathrm{dc}$ reactor to help limit the rate of rise of faulted current and

This work has been supported in part by the School of Electrical and Electronics Engineering, the University of Manchester, and National Grid plc, UK.

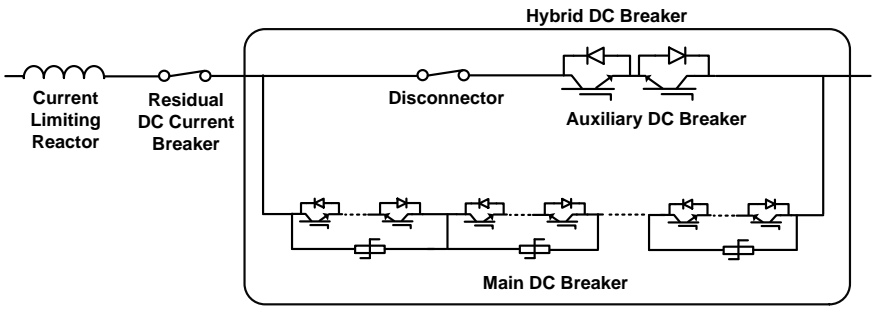

Fig. 1. ABB Proactive VSC-HVDC Circuit Breaker [1].

the rate of reduction of dc voltages. This reactor is also likely to be required for fault detection algorithms [3]. The minimum size of the dc reactor depends on the breaking time of the DCCB, and its maximum current breaking rating, which is directly linked with the cost of the breaker. On the other hand, the dc reactor size is also limited by its cost, and, possibly, the extra conduction loss and stability requirement of the de grid. Values in the order of $100 \mathrm{mH}$ per pole for $\pm 320 \mathrm{kV}$ systems are typically used in previous published work $[1,4]$.

However large dc reactors will extend the electrical distance between converter stations, have a detrimental effect on the $\mathrm{dc}$ voltage control and even affect the stability of HVDC grids. A number of excellent papers exist analyzing dynamics of multiterminal grids [5-9], but none yet examine the impact of this new component. The stability in the level of dc grid can be interpreted as dc voltage stability. The main target of $\mathrm{dc}$ voltage control is to cope with the transient power imbalance in the dc grid and maintain the voltages of all terminals within an acceptable level range. Droop control, which enables a distributed control and a relatively high reliability, has been suggested as the most feasible dc voltage control strategy for MTDC [6-8, 10]. As such, droop control will be used as the benchmark control in this paper for the study of the impact of the de reactor on MTDC dynamics.

The purpose of this paper is to address the limitations imposed by the dc reactor on the stability and dynamic performance of MTDC systems, and show how control can be improved to cope with such issues. This paper approaches these problems from the perspective of both pole-zero analysis and frequency-response analysis, to provide a comprehensive review of the issues. A generalized analytical model for dc voltage stability studies is described in Section II. In Section III, the stability limitations imposed by the dc breaking system are demonstrated and analysed in a simple and generic fourterminal MTDC system. In Section IV, the new dc voltage 


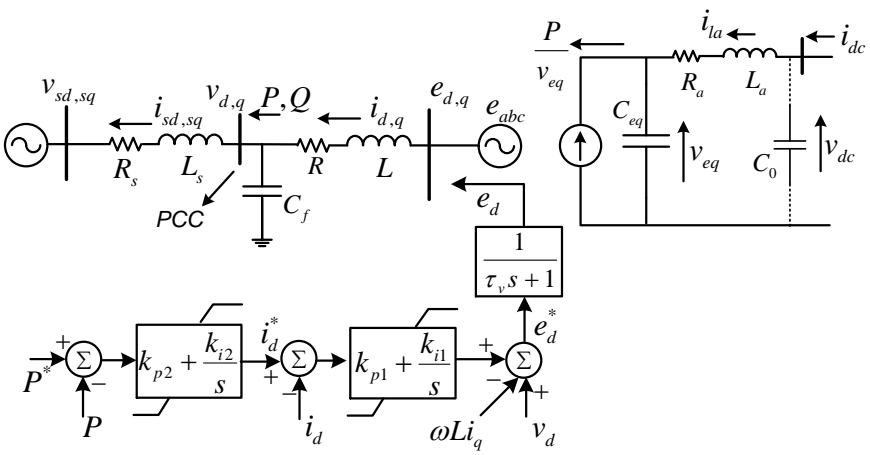

Fig. 2. Representation of VSC-HVDC plant and active power controller.

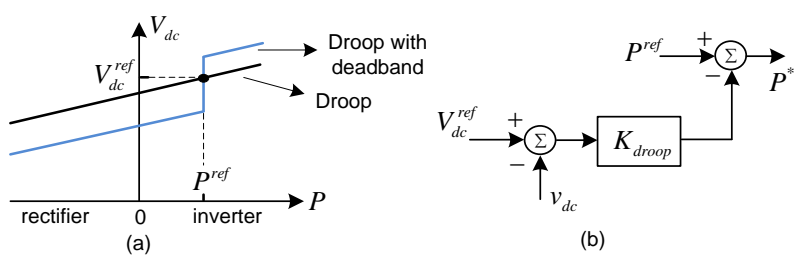

Fig. 3. (a) Typical steady-state characteristics of the V-P droop and the droop with a power deadband. (b) Droop controller implementation.

damping control is proposed to enhance the transient behaviour of systems with large dc reactors. The selection of the controller location and the performance of this damping control are generalized and demonstrated using a more complex seven-terminal MTDC system.

\section{Generalized ANALYTiCAL Modelling}

A generalized mathematical model is derived here in order to perform detailed analytical studies regarding the dc voltage stability of a VSC-HVDC grid.

\section{A. Modelling of onshore converter dynamics}

An average-value VSC model shown in Fig. 2, where the switching dynamics are not explicitly represented, is employed here, as such high-frequency dynamics are of little concern in terms of the dc grid stability. On the ac side, the VSC is modelled as a controlled voltage source. The dc-side VSC model is represented as a controlled current source, based upon the power balance principle and the equivalent circuit typically used for modular multilevel converter (MMC) systems [11].

The converter ac current is typically controlled in a $d q$ synchronous system. A phase-locked loop (PLL) is controlled to enable the alignment of the d-axis and the voltage vector at the point of common coupling (PCC), in order to minimize the coupling between active and reactive power control. For a relatively strong ac system, the q-axis current and reactive power control are likely to have a very limited impact on the active power transfer, since the q-axis PCC voltage is normally maintained to be zero by the PLL $[10,12,13]$. Therefore, the q-axis related controllers are not included here in the analytical model for de voltage stability study, as the focus of this paper is dc system dynamics, not very weak ac system connection.

The dc voltage droop, with its steady-state characteristic and controller implementation shown in Fig. 3, will be employed for the onshore converter stations (OSC) under investigation to form a closed-loop model. The droop with deadband control, which enables the converter power to remain unperturbed when the local dc voltage is within the defined range, can be modelled as a droop controller or an active power controller, depending on the operating condition. For the commonly proposed voltage-power (V-P) droop control [7, 10, 12, 14], the active power reference $P^{*}$ is manipulated by the droop dc voltage controller, and, therefore, the active power control system acts as part of the plant model of the droop control. This section focuses on deriving a state-space model to represent this plant model, based on the system and the notations shown in Fig. 2.

The system dynamics related to the d-axis current can be represented by the following differential equations:

$$
\begin{gathered}
\frac{d \Delta i_{d}}{d t}=\frac{1}{L} \Delta e_{d}-\frac{1}{L} \Delta v_{d}-\frac{R}{L} \Delta i_{d}+\omega \Delta i_{q} \\
\frac{d \Delta i_{s d}}{d t}=\frac{1}{L_{s}} \Delta v_{d}-\frac{1}{L_{s}} \Delta v_{s d}-\frac{R_{s}}{L_{s}} \Delta i_{s d}+\omega \Delta i_{s q}
\end{gathered}
$$

where " $\Delta$ " refers the deviation from the linearized point, $(R+j \omega L)$ is the aggregated impedance of transformer and arm reactor, and $\left(R_{s}+j \omega L_{s}\right)$ is the equivalent grid impedance [10].

The system dynamics associated with the d-axis filter bus voltage can be derived as:

$$
\frac{d \Delta v_{d}}{d t}=\frac{1}{C_{f}} \Delta i_{d}-\frac{1}{C_{f}} \Delta i_{s d}+\omega \Delta v_{q}
$$

Assuming the converter is not connected to a very weak ac system, the drift of the q-axis PCC voltage is likely to be well controlled by the PLL. Therefore, the small-signal form of the inverting power of the VSC can be approximated as:

$$
P=v_{d} i_{d}+v_{q} i_{q} \Rightarrow \Delta P \approx v_{d o} \Delta i_{d}+i_{d o} \Delta v_{d}
$$

Please note that inverting power orientation $(\mathrm{P}>0$, inverter) and per-unit values are used through the paper.

The equivalent converter capacitor $C_{e q}$ is derived based on the total energy stored in the sub-modules [15]. The equivalent arm inductance $L_{a}$ is also modelled in the dc side with its value given by $L_{a}=(2 / 3) L_{a r m}$, as suggested in [11] for average-value MMC models. Assuming the ac power at the PCC is equal to the dc side power, the dynamics of the dc link capacitor can be linearized as:

$$
\frac{d \Delta v_{e q}}{d t}=\frac{\Delta i_{l a}}{C_{e q}}+\frac{P_{o}}{C_{e q} v_{e q o}^{2}} \Delta v_{e q}-\frac{P_{o}}{C_{e q} v_{e q o}} \Delta P
$$

where the subscript "o" refers to the operating point (OP). The voltage $v_{d c}$ across $C_{e q}$ and $L_{a}$ is the dc voltage to be controlled. 
A very small capacitance $C_{0}$ is modelled to enable $v_{d c}$ to be a state variable to facilitate the generalized modelling.

$$
\frac{d \Delta i_{l a}}{d t}=\frac{\Delta v_{d c}}{L_{a}}-\frac{\Delta v_{e q}}{L_{a}}-\frac{R_{a}}{L_{a}} \Delta i_{l a}, \quad \frac{d \Delta v_{d c}}{d t}=\frac{\Delta i_{d c}-\Delta i_{l a}}{C_{0}}
$$

The dynamics of the integrators in the two PI controllers for the $i_{d}$ current and active power control can be described by:

$$
\frac{d \Delta x_{P}}{d t}=k_{i 2}\left(\Delta P^{*}-\Delta P\right), \quad \frac{d \Delta x_{i d}}{d t}=k_{i 1}\left(\Delta i_{d}^{*}-\Delta i_{d}\right)
$$

where the $x_{P}$ and $x_{i d}$ are the two state variables of the two integrators. Based upon the active power controller structure and equation (4), the $i_{d}$ reference can be represented as:

$$
\Delta i_{d}^{*}=k_{p 2}\left[\Delta P^{*}-\left(v_{d o} \Delta i_{d}+i_{d o} \Delta v_{d}\right)\right]+\Delta x_{P}
$$

To enable the state-space formulation, $\Delta P$ and $\Delta i_{d}{ }^{*}$ in (7) need to be substituted with (4) and (8) respectively.

A first-order transfer function (TF) with a time constant $\tau_{v}$ is used to represent the VSC modulation control. This enables the VSC ac voltage $e_{d}$ to become a state variable and therefore facilitates the mathematical modelling. The dynamics related to this state variable can then be described as:

$$
\begin{aligned}
& \frac{d \Delta e_{d}}{d t}=\frac{1}{\tau_{v}}\left(\Delta e_{d}^{*}-\Delta e_{d}\right)= \\
& \frac{1}{\tau_{v}}\left[k_{p 1}\left(\Delta i_{d}^{*}-\Delta i_{d}\right)+\Delta x_{i d}-\omega L \Delta i_{q}+\Delta v_{d}\right]-\frac{1}{\tau_{v}} \Delta e_{d}
\end{aligned}
$$

where the voltage reference $\Delta e_{d}{ }^{*}$ is calculated based on the current controller structure. Note that $\Delta i_{d}{ }^{*}$ in (9) needs to be substituted by (8) for the final state-space formulation.

Based on the 9 differential equations above, a $9^{\text {th }}$-order state-space model is then readily constructed for the $j^{\text {th }}$ onshore converter terminal (OSC) in a MTDC system, in the form of (10), where $P_{j}^{*}$ is the power reference of the $j^{\text {th }}$ converter, $i_{d c(j)}$ is the dc current injected into the $j^{\text {th }}$ converter from the dc grid, $d_{j}$ denotes the disturbance vector ([ $v_{s d} v_{q} i_{q}$ $\left.i_{s q}\right]^{T}$ in this case). The corresponding 9 state variables are listed as shown in (11). The matrices associated with $\Delta v_{d c(j)}$ and $\Delta i_{d c(j)}$ are extracted in order to facilitate the integration of the VSC model and the dc network model.

$$
\begin{aligned}
& \dot{x}_{j}=A_{j} x_{j}+\left[\begin{array}{ll}
B_{j G} & B_{j}
\end{array}\right]\left[\begin{array}{c}
\Delta i_{d c(j)} \\
\Delta P_{j}^{*}
\end{array}\right]+B_{d j} d_{j} \\
& \Delta v_{d c(j)}=C_{j G} x_{j}
\end{aligned}
$$

$x_{j}=\left[\begin{array}{lllllllll}\Delta e_{d} & \Delta v_{d} & \Delta i_{d} & \Delta i_{s d} & \Delta x_{i d} & \Delta x_{P} & \Delta v_{e q} & \Delta v_{d c} & \Delta i_{l a}\end{array}\right]^{T}$

This paper focuses the dynamic relations between the dc voltages and converter powers. The effect of the variables $d_{j}$ will not be discussed. More input/disturbances and output of interest can however be added in this model for other analysis.

Any offshore VSC station is controlled as the local slack ac bus to absorb the power generated by the wind farm and

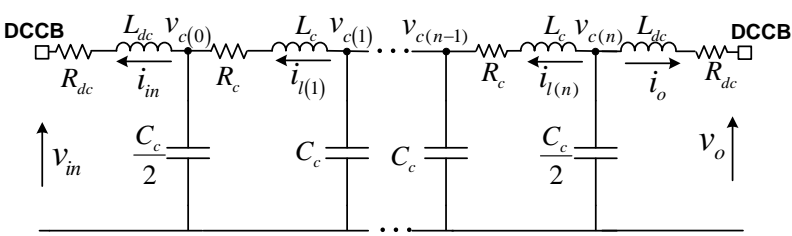

Fig. 4. Circuit of a multi- $\pi$ cable model with de inductances at two ends.

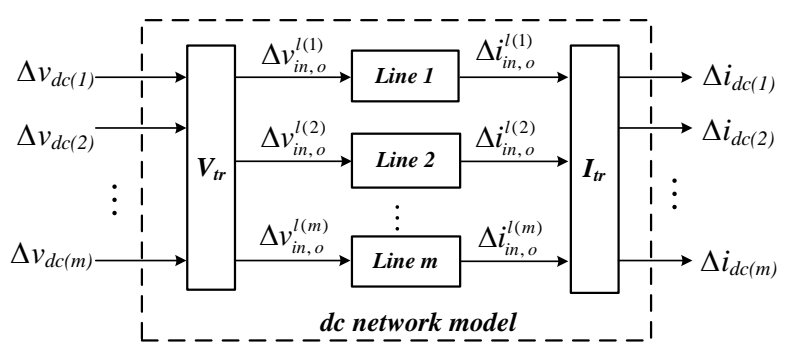

Fig. 5. DC network model integrating multiple line models.

normally does not participate in dc voltage control. From the viewpoint of DC system control, a wind farm side converter (WFC) has similar behavior as an OSC in active power control mode, provided no significant wind power oscillation occurs. An identical dc link model to the OSC is applied for the WFC, while for simplicity, the ac side is modelled as a controlled power source with a time constant representing the simplified dynamics of wind turbine converters. The overall WFC dynamics are also represented in the form of (10).

\section{B. Modelling of dc network}

The dc reactors will be located at the ends of each line in the dc switchyard of the converter station. For a dc line modelled by $n \pi$ sections, as illustrated in Fig. 4, the dynamics of the dc reactors and the $\pi$ sections can be represented by the following $(2 n+3)$ differential equations:

$$
\begin{gathered}
\left.\frac{d v_{c(j)}}{d t}\right|_{j=1,2, \cdots, n-1}=\frac{1}{C_{c}}\left(i_{l(j+1)}-i_{l(j)}\right) \\
\frac{d v_{c(0)}}{d t}=\frac{2}{C_{c}}\left(i_{l(1)}-i_{i n}\right), \quad \frac{d v_{c(n)}}{d t}=\frac{2}{C_{c}}\left(-i_{l(n)}-i_{o}\right) \\
\left.\frac{d i_{l(j)}}{d t}\right|_{j=1,2, \cdots, n}=\frac{1}{L_{c}}\left(v_{c(j)}-v_{c(j-1)}-R_{c} i_{l(j)}\right) \\
\frac{d i_{i n}}{d t}=\frac{1}{L_{d c}}\left(v_{c(0)}-v_{i n}-R_{d c} i_{i n}\right), \frac{d i_{o}}{d t}=\frac{1}{L_{d c}}\left(v_{c(n)}-v_{o}-R_{d c} i_{o}\right)
\end{gathered}
$$

where $L_{d c}$ and $R_{d c}$ represent the inductance and the resistance of the dc reactor respectively. Subsequently, the $(2 n+3)^{\text {th }}$-order state-space model of the $j^{\text {th }}$ line and the associated dc breaking reactors can be written as:

$$
\dot{x}=A_{j}^{\text {line }} x+B_{j}^{\text {line }} u, \quad y=C_{j}^{\text {line }} x
$$

where the dc voltages at the two ends are used as input and the $\mathrm{dc}$ currents out of the line are produced as output: 


$$
\begin{aligned}
& x=[\begin{array}{lllllllll}
\underbrace{v_{c 0}}_{n+1} & v_{c 2} & \cdots & v_{c(n)}
\end{array} \underbrace{\begin{array}{llllll}
i_{i n} & i_{l 1} & \cdots & i_{l(n)} & i_{o}
\end{array}}_{n+2}]^{T} \\
& y=\left[\begin{array}{ll}
i_{\text {in }} & i_{o}
\end{array}\right]^{T}, u=\left[\begin{array}{ll}
v_{\text {in }} & v_{o}
\end{array}\right]^{T}
\end{aligned}
$$

For a dc grid with $n$ converter terminals and $m$ dc lines, based on the modelling structure illustrated in Fig. 5, the dc line models in the form of (14) can then be interconnected to form the state-space model of the overall dc network:

$$
\begin{aligned}
& {\left[\begin{array}{c}
\dot{\mathbf{x}}_{1}^{\text {line }} \\
\dot{\mathbf{x}}_{2}^{\text {line }} \\
\vdots \\
\dot{\mathbf{x}}_{m}^{\text {line }}
\end{array}\right]=\operatorname{diag}\left(\left.A_{j}^{\text {line }}\right|_{j=1, \ldots, m}\right)\left[\begin{array}{c}
\mathbf{x}_{1}^{\text {line }} \\
\mathbf{x}_{2}^{\text {line }} \\
\vdots \\
\mathbf{x}_{m}^{\text {line }}
\end{array}\right]+\operatorname{diag}\left(\left.B_{j}^{\text {line }}\right|_{j=1, \ldots, m}\right) \cdot \mathbf{V}_{t r}\left[\begin{array}{c}
v_{d c(1)} \\
v_{d c(2)} \\
\vdots \\
v_{d c(n)}
\end{array}\right]} \\
& {\left[\begin{array}{c}
i_{d c(1)} \\
i_{d c(2)} \\
\vdots \\
i_{d c(n)}
\end{array}\right]=\mathbf{I}_{T r}\left[\begin{array}{c}
\mathbf{y}_{1}^{\text {line }} \\
\mathbf{y}_{2}^{\text {line }} \\
\vdots \\
\mathbf{y}_{m}^{\text {line }}
\end{array}\right]=\mathbf{I}_{t r} \cdot \operatorname{diag}\left(\left.C_{j}^{\text {line }}\right|_{j=1, \ldots, m}\right)\left[\begin{array}{c}
\mathbf{x}_{1}^{\text {line }} \\
\mathbf{x}_{2}^{\text {line }} \\
\vdots \\
\mathbf{x}_{m}^{\text {line }}
\end{array}\right]}
\end{aligned}
$$

where $\mathbf{V}_{t r}$ is used to transform the vector of the VSC terminal $\mathrm{dc}$ voltages to the voltage vector suitable for the input of line models, and $\mathbf{I}_{t r}$ is used to obtain the vector of the converter dc current from the outputs of the line models, as shown in (17).

$$
\begin{aligned}
& {\left[\begin{array}{lll}
v_{d c(1)} & \cdots & v_{d c(n)}
\end{array}\right]^{T}=\mathbf{V}_{t r}^{-1} \cdot\left[\begin{array}{llllll}
v_{\text {in }}^{\text {line }(1)} & v_{o}^{\text {line }(1)} & \cdots & v_{\text {in }}^{\text {line }(m)} & v_{o}^{\text {line }(m)}
\end{array}\right]^{T}} \\
& {\left[\begin{array}{llllll}
i_{d c(1)} & \cdots & i_{d c(n)}
\end{array}\right]^{T}=\mathbf{I}_{t r} \cdot\left[\begin{array}{lllll}
i_{\text {in }}^{\text {line }(1)} & i_{o}^{\text {line }(1)} & \cdots & i_{\text {in }}^{\text {line }(m)} & i_{o}^{\text {line }(m)}
\end{array}\right]^{T}}
\end{aligned}
$$

\section{Integration of the converter and network models}

A schematic diagram of the multi-input-multi-output (MIMO) plant model used for MTDC voltage stability analysis is shown Fig. 6. This model can be employed for studies on a MIMO controller, however, in this paper, open-loop and closed-loop systems with the more realistic distributed control will be analysed. For the droop control, the power references of the OSCs in dc voltage control mode are employed as the manipulated input. The power variations of the WFCs and the OSC in active power control mode act as disturbances to the dc voltage control. The power "reference" for the WFC is mechanical power captured by the turbine system.

$$
\begin{aligned}
& \dot{x}_{G}=A_{G} x_{G}+B_{G} \Delta \mathbf{v}_{d c} \\
& \Delta \mathbf{i}_{d c}=C_{G} x_{G}
\end{aligned}
$$

By combining the analytical models of all the converter terminals shown in the form of (10) and the dc network model shown in (18) (equivalent to (16)), the overall open-loop statespace model for the dc voltage stability studies can be derived as shown in (19), where $x_{j}$ is the state variables of the $j^{\text {th }}$ converter model, $B_{G j}$ is the $j^{\text {th }}$ column of $B_{G}$, and $C_{G j}$ is the $j^{\text {th }}$ row of $C_{G}, n$ is the total number of converter terminals, $n_{G}$ is the number of state variables of $x_{G}$.

In the following studies, the relevant open-loop transfer functions are extracted from this multivariable model. The closed-loop MTDC model will be formed by connecting droop controllers to this MIMO model.

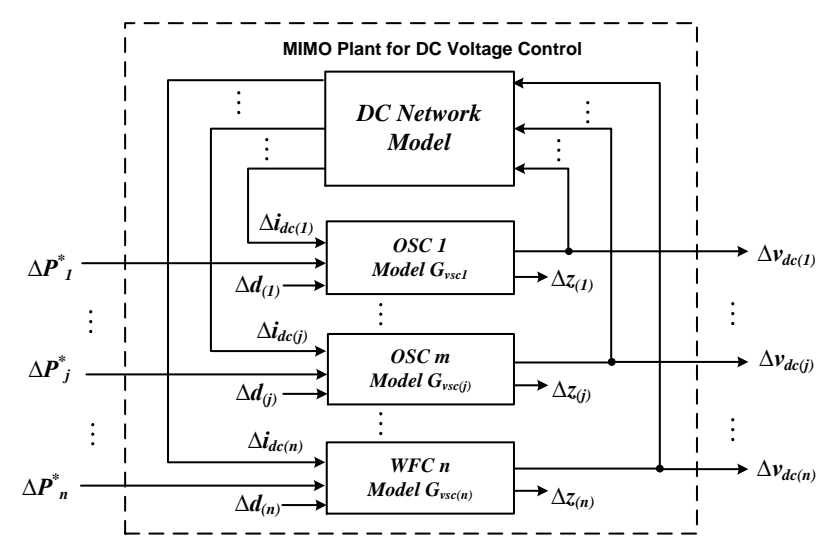

Fig. 6. Formulation of plant model for the dc voltage control.

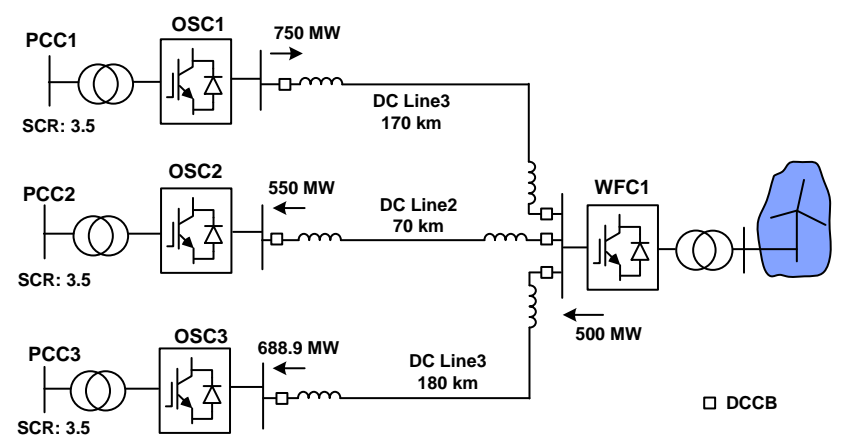

SCR: 3.5

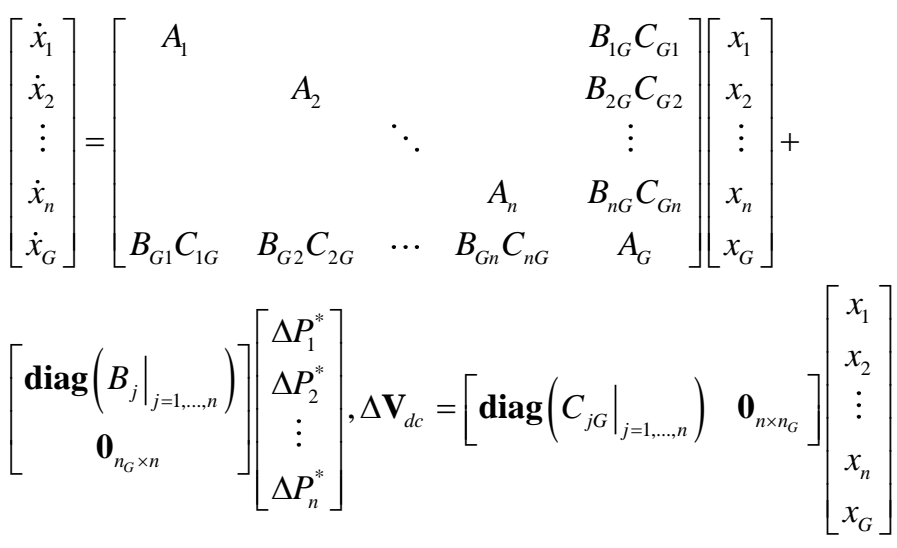

\section{ANALYSIS OF STABILITY AND PERFORMANCE ISSUES}

A four-terminal VSC-HVDC system, with its topology and the nominal power flow shown in Fig. 7, is employed as the candidate system to demonstrate the stability and performance issues revealed in this section. Each converter station is rated at $1000 \mathrm{MW}, \pm 320 \mathrm{kV}$, and a symmetrical monopole topology is used. The nominal dc reactor of $100 \mathrm{mH}$ per pole is selected for the dc breaker system.

\section{A. Stability and controllability issues}

The droop control is essentially a proportional dc voltage controller. Root locus analysis based on the plant model is very effective to analyze controllability and to determine the 


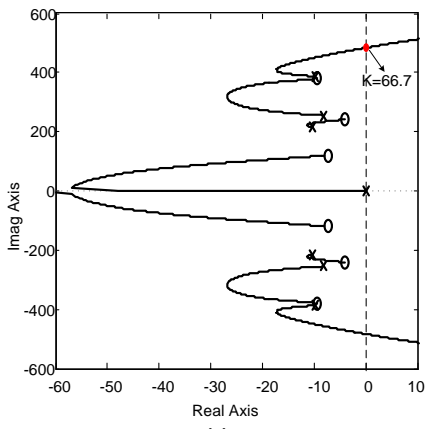

(a)

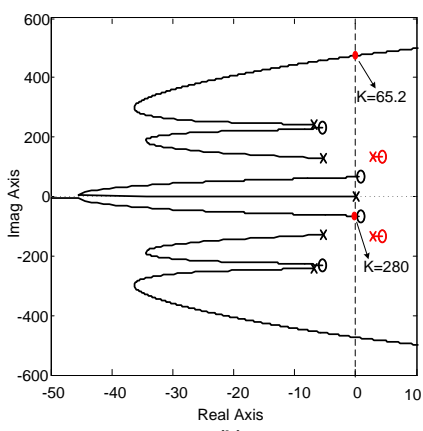

(b)

Fig. 8. Root loci of the transfer function of $v_{d c l}(s) / P_{I} *(s)$ in low-frequencies, without dc reactor (a), with dc reactor of $100 \mathrm{mH}$ (b).

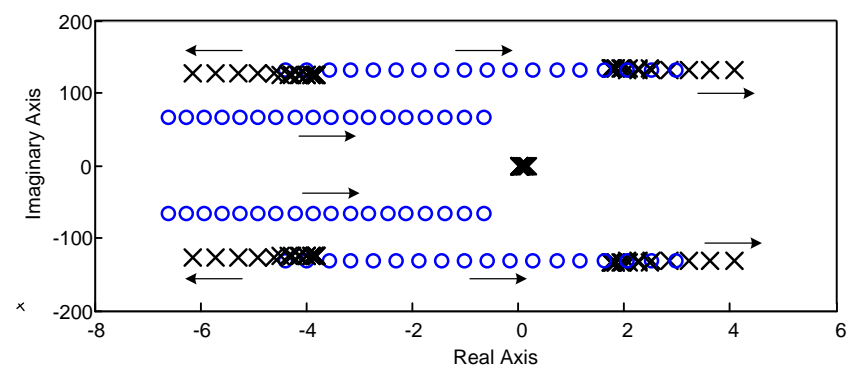

Fig. 9. Trajectories of the dominant poles and zeroes of the open-loop TF $v_{d c 3}(s) / P_{3}{ }^{*}(s)$ as OSC3's inverting power varies from $0.85 \mathrm{pu}$ to $-0.45 \mathrm{pu}$.

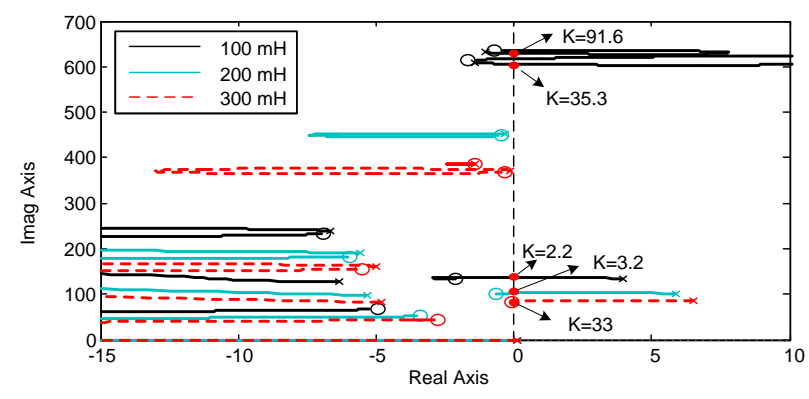

Fig. 10. Root loci of the plant model $v_{d c 3}(s) / P_{3}{ }^{*}(s)$ for three dc inductor sizes.

appropriate droop gain. For a particular VSC terminal, the plant of its droop controller is the transfer function (TF) between its power reference $P_{j}^{*}(s)$ and the local dc voltage $v_{d c j}(s)$, which can be directly extracted from the MIMO model. The controllability analysis is performed based upon the openloop plant models of the dc voltage control, in order to present the general stability issues imposed by the dc reactor, despite the controller parameterization. The limitations imposed by the $\mathrm{dc}$ reactor on the dc voltage controllability and stability are investigated by analysing the loci of poles and zeros.

With respect to $v_{d c}$ control using OSC1, the root loci of the plant model $v_{d c l}(s) / P_{l}{ }^{*}(s)$ is show in Fig. 8 (a) and (b), for the four-terminal model without and with consideration of the dc reactors in the system, respectively. Only the low-frequency dominant poles and zeros out of the hundreds in the system are shown here for clarity. Including the $100 \mathrm{mH}$ dc reactors significantly worsens the controllability of the system, since there are right-half-plane (RHP) poles and zeros located close to each other, as shown in Fig. 8 (b).

It is acknowledged in [16] that, large peaks of sensitivity in a transfer function are unavoidable when RHP poles are close to RHP zeros, and, therefore, such systems will be very difficult to stabilize and a high-order controller will have to used. The root loci in Fig. 8(b) suggest that, when there is no other converter in $v_{d c}$ control mode, the dc voltage is uncontrollable by OSC1 using droop control, despite the droop gain setting. In fact, the dc reactor imposes a severe constraint for all types of de voltage control using OSC1, including de slack bus control and voltage margin control. An increased number of converters need to be configured in dc voltage control mode in order to stabilize the dc system installed with $\mathrm{dc}$ reactors. It is possible that dc slack bus control using only one converter is not feasible for such dc systems.

For a MTDC system with dc breaker systems, its dynamics are likely to be quite sensitive to the variations of the power flow condition of the network. This is demonstrated by Fig. 9, where the trajectories of the dominant poles and zeros of the plant model $v_{d c 3}(s) / P_{3}{ }^{*}(s)$ of dc voltage control using OSC3 are shown, for a range of power flow scenarios, in which the powers of OSC3 and OSC1 are varied while the powers of OSC2 and WFC1 are kept constant.

The dominant poles and zeros migrate towards the RHP as the rectifying power of OSC3 increases. Especially, the lowfrequency zeros are highly sensitive to the power flow of the local terminal as well as the dc network. This effect is mainly caused by the underlying nonlinearity in (5). Such nonlinearization is inevitable as essentially the dc side control of VSC relies on the ac side d-axis current control, which is directly correlated with active power rather than dc current. The RHP poles impose a lower bound of the dc voltage control bandwidth. The RHP zeros however imply high-gain instability and an upper bound of the bandwidth [16].

This robustness issue with respect to the converter power flow exists, even without including large dc reactors in the model. However, the increase of the inductances in the dc system significantly worsens this issue by amplifying the sensitivity of the poles/zeros to the power flow. It is preferable to implement voltage droop control for the converters which usually operate as inverters. For better robustness, droop control is also suggested to be applied to the converters which are likely to experience power reversals. The converter may need to change its control mode in case of extreme power flow changes. More advanced robust controller design may be required to ensure the stability of a dc grid where the power flow could vary significantly and frequently.

For three settings of the dc reactor size, root loci of the plant model $v_{d c}(s) / P_{3}{ }^{*}(s)$ regarding the dc voltage control using OSC3 are shown in Fig. 10. This analysis demonstrates that, larger size of dc inductance implies tighter constraints on the boundaries of droop control gain. This low-gain instability feature has been briefly explained in [10]. As the unstable poles move towards the RHP as the inductance increases, a high-gain controller may have to be employed to obtain a stable system. Furthermore, for the $200 \mathrm{mH}$ and $300 \mathrm{mH}$ scenarios, it is very difficult to achieve a satisfactory dynamic 


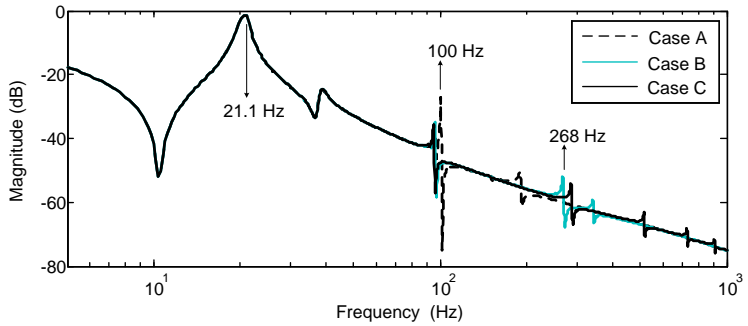

Fig. 11. Frequency response of the open-loop $\mathrm{TF} v_{d c l}(s) / P_{I} *(s)$, for three scenarios of $\pi$ models (Case A: single $\pi$ model for all three cables; Case B: $70 \mathrm{~km}$ per $\pi$ section; Case C: $35 \mathrm{~km}$ per $\pi$ section).

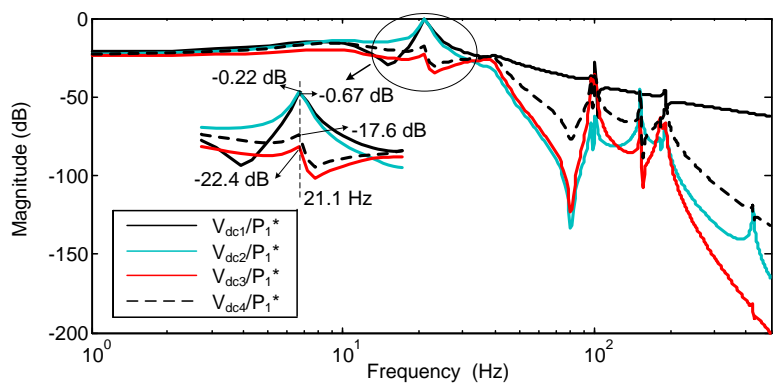

Fig. 12. Frequency responses of the closed-loop TFs between the dc voltages of the four terminals and $P_{I}{ }^{*}(s)$, with droop controller at OSC3 $\left(K_{\text {droop }}=15\right)$.

performance since the damping of the dominant closed-loop poles would be excessively low due to the location of the zeros. This clearly shows that, the control requirement imposes a bound on the maximum dc reactor size, which is also dependent on the specific network topologies and power flow condition.

It should be noted that, for a HVDC grid which has larger equivalent capacitances and resistances, the dc system will be more stable and better damped, and therefore may allow dc reactors with higher ratings to be utilized.

Generally, to improve the stability of dc grids with large dc reactors, voltage droop control systems with carefully designed bandwidth/gains and selected location, should be adopted by more converters, particularly for inverters.

\section{B. Dynamic performance issues}

Frequency-response analysis is employed here to intuitively address the dynamic performance issues caused by large dc reactors. This analytic tool is very useful in interpreting the damping, the robust performance and the key oscillating frequencies of a complex dynamic system.

With three types of $\pi$-model configuration of the cables, the frequency responses of the open-loop model $v_{d c l}(s) / P_{I}{ }^{*}(s)$ are shown in Fig. 11. Given the frequency range of interest, cable models of appropriate fidelities for dc grid stability study can be determined based on such analysis. The single- $\pi$ cable models are sufficiently accurate up to $100 \mathrm{~Hz}$. Case C is used for dynamic studies of the four-terminal model. Similar results can be obtained by performing the frequency-response analysis for other transfer functions extracted from the MIMO plant model. Given that this paper focuses on the slow transients below $50 \mathrm{~Hz}$, the multiple- $\pi$ model is selected for simplicity,

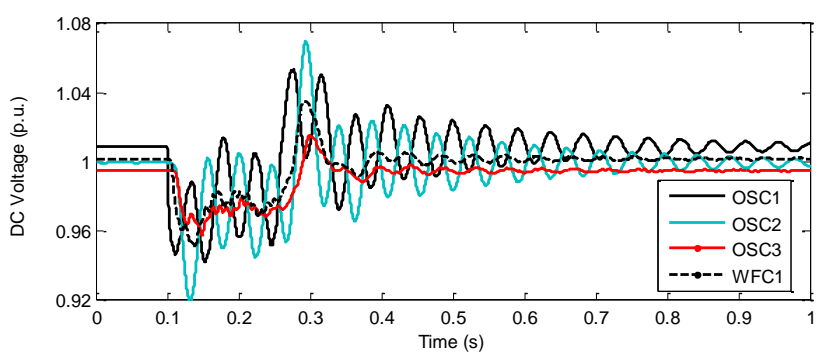

Fig. 13. Responses of the dc voltages to a $50 \%$ voltage sag caused by a fault at PCC1 (droop controller at OSC3, $K_{\text {droop }}=15$ ).

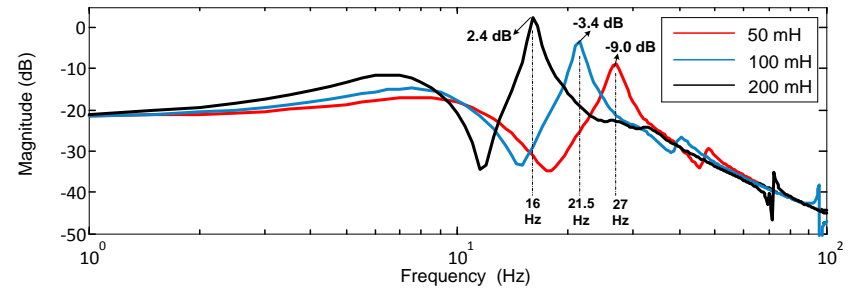

Fig. 14. Frequency response of the closed-loop $\mathrm{TF} v_{d c l}(s) / P_{I}(s)$ for three sizes of dc reactors, with droop controller at $\operatorname{OSC} 3\left(K_{\text {droop }}=15\right)$.

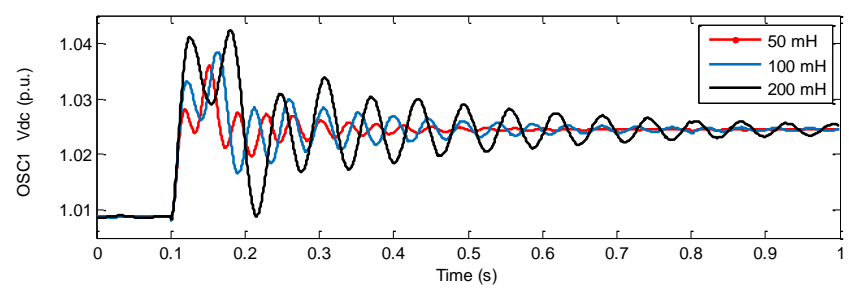

Fig. 15. Response of the dc voltage of OSC1 to a 0.2 p.u. step change of the power reference $P_{1}{ }^{*}$, with droop controller at $\operatorname{OSC} 3\left(K_{\text {droop }}=15\right)$.

as the more detailed frequency-dependent model does not provide more insightful information of the low-frequency transients.

The low-frequency peak at $21.1 \mathrm{~Hz}$ in Fig. 11 implies that the dc voltage at OSC1 could be highly sensitive to the power reference change of OSC1 at such a frequency. If dc voltage is controlled by other terminals, the closed-loop bandwidth may need to be higher than $21.1 \mathrm{~Hz}$ in order to damp the resonance peak. This low-frequency resonance of the open-loop model will be reflected in the closed-loop model.

The frequency responses of the transfer functions between the four terminal voltages and the power deviation of OSC1 of a closed-loop model are shown in Fig. 12. In this closed-loop system, OSC3 uses droop control with a gain of 15, OSC2 employs droop control with a power deadband (deadband $v_{d c}$ range: $0.92-1.06$ p.u.), and OSC1 is in power control mode. Since the analytical model is based on the nominal OP, OSC2 is modelled in the same way as it is in power control mode.

In a MTDC system with dc reactors, the dynamic behaviors of dc voltages at different terminals may differ significantly. This is mainly due to that the increase of dc inductances effectively slowing down the propagation of dynamic changes of dc currents from one terminal to another. As shown in Fig. 12 , the frequency peaks of transfer functions associated with 


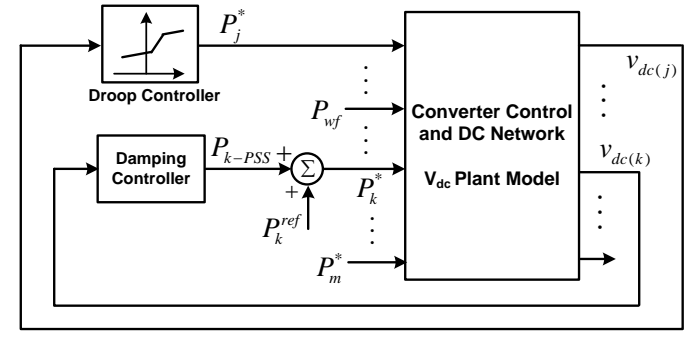

Fig. 16. Generalized closed-loop model for dc voltage control in MTDC systems with damping controllers.

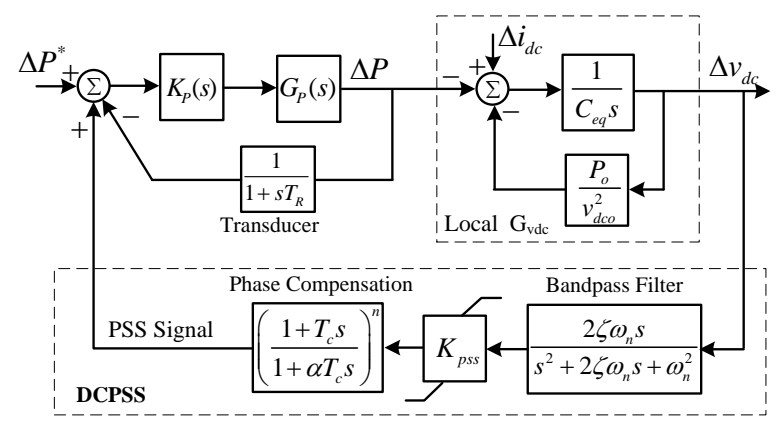

Fig. 17. DC voltage damping controller structure.

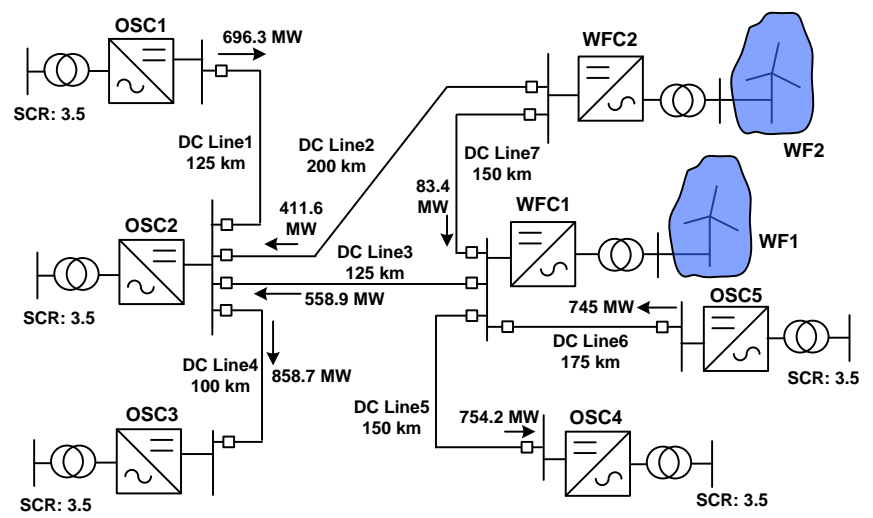

Fig. 18. Network diagram of the seven-terminal HVDC test model.

OSC1 and OSC2 are much higher than those with OSC 3 and OSC4. The frequency-domain peak is a very effective performance measure of the closed-loop system behaviour, in this case, the responses of dc voltages to a power disturbance. Larger frequency-domain peaks normally indicate poorer transient performance and robustness [16]. This indicates a serious performance issue, that the dc voltages of the terminals in active power control mode could lack damping. Global dc voltage control, which is implemented based on several local $v_{d c}$ measurements, may not be able to ensure satisfactory performance of all the dc terminal voltages when the resonance peaks resulting from the meshed dc circuit exist.

A time-domain simulation was performed to verify the frequency-response analysis, with the dc voltage responses to a fault at the PCC bus of OSC1 shown in Fig. 13. The fault, which results in a $50 \%$ sag of the ac voltage at PCC1, occurred at $0.1 \mathrm{~s}$ and is cleared after $150 \mathrm{~ms}$. All the electromagnetic simulations are performed on an average-value VSC model using DIgSILENT PowerFactory. In case of the sudden power variation of $\mathrm{OSC} 1$, the dc voltages of OSC1 and OSC2 experienced severe oscillations, especially when OSC2 was in the power deadband mode. In contrast, the dc voltages of the OSC 3 and WFC1 are much better damped. This confirms the frequency responses shown in Fig. 12. Furthermore, the key oscillation frequency in Fig. 13 agrees very well with frequency domain results. Please note that, for a more complete analysis of the disturbance rejection performances of the dc voltage control as would be required for an actual implementation, the frequency responses with respect to the transfer functions between the dc voltages and the power variations of all the converters need to be evaluated.

When OSC3 operates in droop control mode while other OSCs are in power control mode, the impact of the dc reactor size on the frequency response of the TF between $v_{d c l}$ and the power deviation of OSC1 is shown in Fig. 14. For systems with larger dc reactors, the frequency-response peak tends to be larger and located at lower frequency, and this implies that, the oscillations of the corresponding dc voltages in case of power imbalance in the dc system are more severe. Similar behaviors can be observed from the TFs between dc voltages and power variations of other terminals. The frequencyresponse analysis is verified by the simulation provided in Fig. 15 , which shows the dc voltage responses to the change of power reference of OSC1. Increasing the dc reactor could significantly deteriorate the dynamic dc voltage performance of the converters which do not participate in dc voltage control. The issue could be alleviated by engaging the underdamped converters with transient dc voltage control.

The next section will provide a new transient dc voltage controller to tackle the dynamic performance issue.

\section{DC Voltage DAmping Controller}

A dc damping controller similar to a power system stabilizer (PSS), termed as a DCPSS, is developed in this paper to provide transient damping for dc voltage and improve the stability of the dc network by modifying converter power control using a supplementary stabilizing signal. A typical closed-loop MTDC model with such damping controllers is illustrated in Fig. 16. During transients, the voltages of the dc grid are regulated by the droop control together with the DCPSS to reject the power disturbances coming from other terminals. In steady states, an OSC equipped with the DCPSS behaves like a typical converter in the active power control mode. As the speed deviation is normally used by the PSS in generator systems, the locally measured dc voltage, which is the indicator of power balance in dc system, acts as the input for the DCPSS.

As shown in Fig. 17, the DCPSS controller is comprised of a bandpass filter (BPF), a phase compensator, and a stabilizer gain. The bandpass filter not only allows the $v_{d c}$ oscillations to pass as the washout in the PSS, but also prevents the damping controller from reacting to fast dynamics above certain 
frequency threshold. The phase compensation is designed to compensate the phase difference between the PSS output and converter power output, in order to produce a component of dc current roughly in phase with the $v_{d c}$ variations.

To demonstrate the generalization of the modelling method and the analysis approach presented in Section II and III, a more complex seven-terminal MTDC model, with its schematic diagram shown in Fig. 18, is employed for the studies on the DCPSS. DC reactors of $100 \mathrm{mH}$ are utilized in the model. The system is also built in PowerFactory to perform time-domain simulations.

Singular value analysis has been used to select the DCPSS location, cross-verified with participation factor analysis. The methods can also be directly applied to identify the appropriate location for dc voltage droop control.

The singular value method, which is the equivalent frequency response for multivariable systems and provides insightful information on the gains between multiple output and input [16], and is employed here to assess the gain between the dc voltages of all the terminals and the power reference of a particular VSC terminal. A singular value plot shows the gains between the Euclidean norm of the output vector and that of the input vector in frequency domain [16]. An OSC with large singular values in the frequency range of interest implies that the dc voltages of the overall system is likely to be sensitive to the power variation of this OSC, and, therefore, it can be a desirable site for the DCPSS.

When OSC1 and OSC2 operate in droop control mode with droop gains of 7 and 15 respectively, and OSC3-5 operate in power control mode, the singular values between the $\boldsymbol{v}_{d c}$ vector and the power set-points of the selected terminals, are shown in Fig. 19 for this closed-loop model.

The singular value between the all the terminal voltages and the power of OSC 3 has the highest peak. This shows that the OSC3 is suitable for the installation of the DCPSS, because the power of OSC3 generally has a larger impact on the dc voltage around the resonant frequency $(18.3 \mathrm{~Hz})$. Additionally, WFCs have relatively lower impact on the dc voltages at low frequencies, which indicates a relatively good disturbance rejection capability of the system regarding the wind power changes.

Participation factor analysis has been adopted for the identification of PSS in a multi-machine system [17, 18]. The participation factors corresponding to the $i$ th mode eigenvalue can be interpreted as [19]:

$$
\mathbf{p}_{i}=\left[\begin{array}{llll}
\phi_{1 i} \psi_{i 1} & \phi_{2 i} \psi_{i 2} & \cdots & \phi_{n i} \psi_{i n}
\end{array}\right]^{T}
$$

where $\psi$ and $\phi$ are the left and right eigenvectors respectively. The element $p_{j i}$ reflects the relative participation of the $j$ th state in the $i$ th eigenvalue (mode) [19].

In the participation factor method, firstly the dominant oscillating modes need to be identified by computing the eigenvalues. It is observed that the dc terminal voltages are the state variables which generally have large participation factors in the poorly damped eigenvalues, in analogy to the frequency

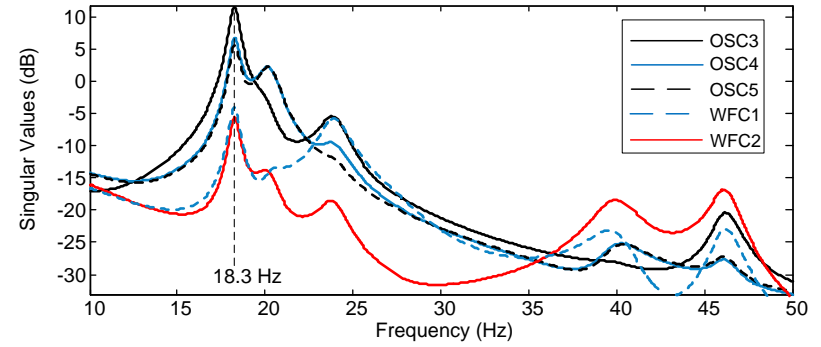

Fig. 19. Singular value plots of the closed-loop models with all the dc terminal voltages as output and the power of selected terminal as input (OSC1: $K_{\text {droop }}=7$; OSC $2: K_{\text {droop }}=15$ ).

TABLE I

SELECTED PARTICIPATION FACTORS FOR THE SEVEN-TERMINAL SyStem

\begin{tabular}{c|c|c|c|c|c}
\hline Eigenvalues & OSC1 & OSC2 & OSC3 & OSC4 & OSC5 \\
\hline$-1.69 \pm j 115$ & 0.047 & 0.037 & $\mathbf{0 . 3 6 7}$ & 0.101 & 0.100 \\
$-4.07 \pm j 127$ & 0.005 & 0.003 & 0.062 & 0.229 & 0.323 \\
$-5.35 \pm j 150$ & 0.068 & 0.014 & 0.161 & 0.051 & 0.045 \\
$-4.84 \pm j 290$ & 0.030 & 0.348 & 0.021 & 0.003 & 0.003 \\
\hline
\end{tabular}

in ac system [18]. Therefore, the participation factors associated with the dc voltages of each converter terminal are calculated for the modes of interest.

For the seven-terminal system, with respect to the $v_{d c}$ of the OSCs, the participation factors corresponding to the lowfrequency poorly damply modes are calculated as shown in Table I. OSC3 is selected as the desired converter station for the installation of DCPSS, due to its significant participation in the most poorly damped mode. The frequency of this mode is identified as the same with the frequency of the singular value peak in Fig. 19. This participation-factor method yields an identical DCPSS location as the singular-value approach.

It should be noted that, the candidate terminal, which is identified as the suitable site for the DCPSS using the methods above, requires further controllability analysis using root locus or frequency response based on the plant model. The next procedure is the parameterization for the DCPSS. The frequency range of interest can be identified by observing the frequencies where the singular value peaks occur, such as the 15-25 Hz range shown in Fig. 19. A wider frequency range is suggested for the bandpass filter as the frequency-domain peaks may vary with the operating condition of the system. Although the DCPSS is used to enhance the damping of selected modes of oscillations, phase compensation is designed for a range of frequencies rather than a single frequency. To compensate the lag of the power control loop, the phase lead can be designed disregard the control of other terminals. With the BPF and the compensator ready to use, the gain of the DCPSS is selected by performing root locus analysis, to identify the point where sufficient damping is achieved [19].

\section{TEST OF DAMPING CONTROLLERS}

The performance of the proposed damping controllers are evaluated using transient simulations of the seven-terminal model. The configured control modes and droop gains for the 
TABLE II

CONTROL Modes AND DROOP GAINS OF OSCS FOR CASE 1 AND 2

\begin{tabular}{c|c|c|c|c}
\hline & OSC1 & OSC2 & OSC4 & OSC5 \\
\hline Case 1 & $\mathrm{~K}_{\text {droop }}: 7$ & $\mathrm{~K}_{\text {droop }}: 15$ & P control & P control \\
\hline Case 2 & $\mathrm{~K}_{\text {droop }}: 7$ & $\mathrm{~K}_{\text {droop }}: 15$ & $\mathrm{~K}_{\text {droop }}: 10$ & P control \\
\hline
\end{tabular}

TABLE III

DCPSS PARAMETERS FOR TwO CASE STUDIES

\begin{tabular}{c|c|c}
\hline Parameter & Case 1 & Case 2 \\
\hline Gain $\mathrm{K}_{\mathrm{pss}}$ & 12.1 & 8.5 \\
$T_{c}$ & 0.0282 & 0.0279 \\
$\alpha$ & 0.10 & 0.07 \\
BPF Range & $15-35 \mathrm{~Hz}$ & $15-35 \mathrm{~Hz}$ \\
\hline
\end{tabular}

OSCs in the two case studies are shown Table II. In Case 1, OSC1 and OSC2 are selected to operate in droop control mode. In Case 2, another droop controller is added for OSC4 to strengthen the dc voltage stability. OSC3 is selected as the site for DCPSS. The parameters of the damping controller, shown in Table III, are designed based on the methodology discussed in Section IV.

For a sudden loss of $250 \mathrm{MW}$ wind generation at WF2 in Case 1, the selected responses of dc voltages and powers are compared in Fig. 20, with OSC3 operates in three control modes: power control, droop $v_{d c}$ control and the DCPSS control. The power imbalance in the dc network caused by the wind farm is shared by the terminals in droop control.

The transient simulations show the feasibility of the location and design of the DCPSS. The damping of the dc voltage of OSC3 is significantly improved by replacing the conventional active power control with the DCPSS. The performance of the DCPSS is slightly better than $v_{d c}$ droop control, as shown by the de voltages of both OSC3 and OSC4 as well as the power variation of $\mathrm{OSC} 3$, in that the power of $\mathrm{OSC} 3$ is utilized more efficiently by the DSPSS to damp the poorly damped modes than the droop control. Furthermore, unlike the droop control, the steady-state power of OSC3 remains as the pre-transient level when the DCPSS is adopted.

The damping improvement is however limited for the dc voltage of OSC4, as the oscillations in OSC4 cannot be directly sensed by the damping controller located at $\mathrm{OSC} 3$ due to the large electrical distance between the converters. The responses of $\mathrm{OSC} 3$ and $\mathrm{OSC} 4$ to a fault at the PCC bus of OSC5 are shown in Fig. 21, with three types of control applied to OSC3. The fault at PCC5, which resulted in a 70\% voltage drop, occurred at $0.1 \mathrm{~s}$ and was cleared after $200 \mathrm{~ms}$. When OSC3 was in power control mode, and the MTDC stability was maintained by three OSCs out of five, the transient voltage of OSC4 was controlled within an acceptable range however the dc voltage of OSC 3 experienced severe oscillations. The comparison of the controllers for OSC 3 clearly demonstrates the damping enhancement provided by the DCPSS, as both the amplitude and duration of the dc voltage oscillations are significantly reduced.
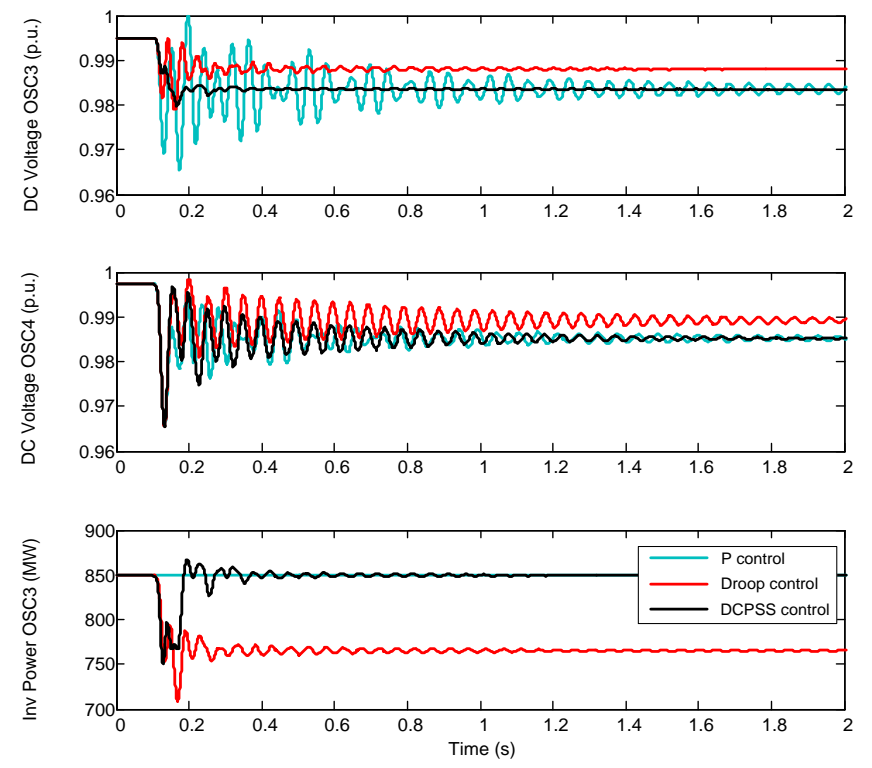

Fig. 20. Responses of the dc voltage and power of OSC3 and OSC4 to a loss of $250 \mathrm{MW}$ generation in wind farm 2, with three types of control applied to OSC3 (Case 1: OSC1 and OSC2 in droop mode).
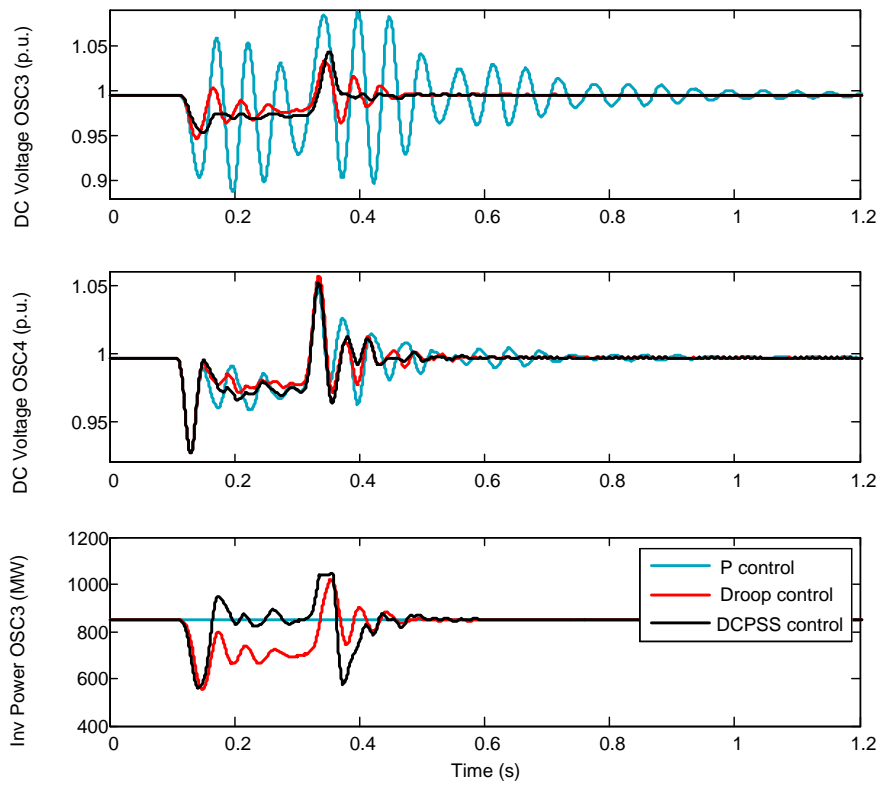

Fig. 21. Responses of the de voltage and power of OSC3 and OSC4 to a fault occurring at PCC5, with three types of control applied to OSC3 (Case 2: OSC1, OSC2 and OSC4 in droop control).

Generally, the damping of the system can also be improved by utilizing a more widespread distributed dc voltage control, as shown by Fig. 20 and Fig. 21. However, it is worth noting that purely increasing the number of $v_{d c}$ controllers does not necessarily improve the damping performance as the location and design of the controller also matter.

The use of the DCPSS has several advantages over incorporating more terminals in droop control. Firstly, the power transfer for the converter with DCPSS control is only perturbed during the fast $\mathrm{dc}$ transients. Therefore, this feature facilitates the power flow control and allows the DCPSS to be used for converters connected with relatively weak ac grids, 
TABLE IV

LOW-FREQUENCY MODES WITH AND WITHOUT DCPSS (CASE 1)

\begin{tabular}{l|l|l|l}
\hline \multicolumn{2}{l|}{ Without DCPSS } & \multicolumn{2}{l}{ With DCPSS } \\
\hline freq $(\mathrm{Hz})$ & $\zeta$ & freq $(\mathrm{Hz})$ & $\zeta$ \\
18.31 & 0.015 & 22.61 & 0.117 \\
23.89 & 0.036 & 45.22 & 0.126 \\
46.34 & 0.017 & 52.23 & 0.087 \\
\hline
\end{tabular}

TABLE V

LOW-FREQUENCY MODES WITH AND WITHOUT DCPSS (CASE 2)

\begin{tabular}{l|l|l|l}
\hline \multicolumn{2}{l|}{ Without DCPSS } & \multicolumn{2}{l}{ With DCPSS } \\
\hline freq $(\mathrm{Hz})$ & Damping $\zeta$ & freq $(\mathrm{Hz})$ & Damping $\zeta$ \\
18.63 & 0.041 & 13.03 & 0.279 \\
23.09 & 0.049 & 22.13 & 0.125 \\
46.34 & 0.017 & 47.29 & 0.043 \\
\hline
\end{tabular}

unlike the droop control, which is normally attached to the terminals supported by strong ac systems. Furthermore, with appropriate location and the phase compensation, the poorly damped poles are more effectively targeted by the DCPSS than droop control, and, therefore, better damping performance can be achieved. The DCPSS controller can also be employed by multiple converters simultaneously.

The enhancement of the damping on the critical modes is also demonstrated by the analytical results shown in Table IV and V, for the application of DCPSS in Case 1 and Case 2, respectively. The oscillating frequency and the damping ratio $\zeta$ for the poorly damped modes are calculated for the closedloop MIMO model with and without the DCPSS in OSC3. As the location of the DCPSS is selected to target the lowfrequency modes with the poorest damping, the damping of such modes is improved most dramatically. Furthermore the DCPSS also has a very positive impact on the damping for the modes of a range of frequencies. In fact, the DCPSS can not only enhance the dynamic performance but also enlarge the stability margins. The modes in dc systems are generally less damped than those in a typical power system, mainly due to lack of the equivalent inertia (capacitance). This eigenvalue analysis agrees well with the time-domain simulations.

\section{CONCLUSION}

Regarding dc voltage stability, a generalized formulation of analytical modelling of MTDC systems including the key dynamics of VSC stations and dc network has been developed.

Based on the four-terminal analytical model, root locus and frequency domain analysis have been adopted to identify the fundamental stability and performance issues related to the dc reactors. The controllability regarding the dc voltage control can be significantly degraded by the use of dc reactor. This component also has a detrimental effect on the robustness of MTDC dynamics to the power flow variation. The high sensitivity of the dynamics to the operating point could impose a serious robustness issue, despite the controller types. For a MTDC system which does not have a widespread dc voltage control, the use of a large dc reactor could result in undesired oscillations of de voltages and even instability.

The DCPSS controller has been proposed to enhance the dynamic performance of the dc voltage control in a dc grid. The transient simulations and eigenvalue analysis for the seven-terminal HVDC model have demonstrated the excellent performance of the damping controller. The selection methods for the DCPSS are also effective for the droop control.

Further work is required to improve the robust stability of the dc grids with dc breaking systems. This paper suggests reducing the number of converters in constant active power control mode, applying DCPSS control to more converters, and employing a more widespread droop control.

The modelling, design and analysis approaches presented in this paper provide a framework on stability studies for more complex MTDC systems.

\section{APPENDIX}

TABLE VI

MTDC SYSTEM PARAMETERS

\begin{tabular}{|c|c|}
\hline DC inductance $\mathrm{L}_{\mathrm{dc}}$ & $100 \mathrm{mH}$ \\
\hline Arm inductance $\mathrm{L}_{\mathrm{arm}}$ & $45 \mathrm{mH}$ \\
\hline Transformer reactance & $0.15 \mathrm{pu}$ \\
\hline Transformer X/R ratio & 30 \\
\hline Equivalent dc capacitance $\mathrm{C}_{\mathrm{eq}}$ & $98 \mu \mathrm{F}$ \\
\hline Equivalent switching time constant $\tau_{v}$ & $82 \mu \mathrm{s}$ \\
\hline Cable resistance per km per pole & $0.0113 \Omega / \mathrm{km}$ \\
\hline Cable inductance per km per pole & $0.46 \mathrm{mH} / \mathrm{km}$ \\
\hline Cable capacitance per km per pole & $0.28 \mu \mathrm{F} / \mathrm{km}$ \\
\hline Current controller gains $\left(\mathrm{k}_{\mathrm{p} 1}, \mathrm{k}_{\mathrm{i} 1}\right)$ & $(1.12,11.77) \mathrm{pu}$ \\
\hline Power controller gains $\left(\mathrm{k}_{\mathrm{p} 2}, \mathrm{k}_{\mathrm{i} 2}\right)$ & $(0.05,78.54) \mathrm{pu}$ \\
\hline
\end{tabular}

For the $j^{\text {th }}$ converter model, the parametric representations of the matrices in (10) are:

$$
\begin{aligned}
& {\left[\begin{array}{rrrrrrrrrrrr}
-\frac{1}{\tau_{v}} & \frac{1-k_{p 2} k_{p 1} i_{d o}}{\tau_{v}} & \frac{-k_{p 2} k_{p 1} v_{d o}-k_{p 1}}{\tau_{v}} & 0 & \frac{1}{\tau_{v}} & \frac{k_{p 1}}{\tau_{v}} & 0 & 0 & 0 \\
0 & 0 & \frac{1}{C_{f}} & -\frac{1}{C_{f}} & 0 & 0 & 0 & 0 & 0 & & \\
\frac{1}{L} & -\frac{1}{L} & -\frac{R}{L} & 0 & 0 & 0 & 0 & 0 & 0 & & \\
0 & \frac{1}{L_{s}} & 0 & -\frac{R_{s}}{L_{s}} & 0 & 0 & 0 & 0 & 0 & & \\
0 & -k_{p 2} i_{d o} k_{i 1} & -\left(k_{p 2} v_{d o}+1\right) k_{i 1} & 0 & 0 & k_{i 1} & 0 & 0 & 0 \\
0 & -k_{i 2} i_{d o} & -k_{i 2} v_{d o} & 0 & 0 & 0 & 0 & 0 & 0 & \\
0 & -\frac{i_{d o}}{v_{d c o} C_{e q}} & -\frac{v_{d o}}{v_{d c o} C_{e q}} & 0 & 0 & 0 & \frac{P_{o}}{C_{e q} v_{d c o}^{2}} & 0 & \frac{1}{C_{e q}} \\
0 & 0 & 0 & 0 & 0 & 0 & 0 & 0 & -\frac{1}{C_{o}} & &
\end{array}\right.} \\
& B_{j G}=\left[\begin{array}{lllllllll}
0 & 0 & 0 & 0 & 0 & 0 & 0 & \frac{1}{C_{o}} & 0
\end{array}\right]^{T}
\end{aligned}
$$




$$
\begin{aligned}
& B_{j}=\left[\begin{array}{ccccccccc}
\frac{k_{p 2} k_{p 1}}{\tau_{v}} & 0 & 0 & 0 & k_{p 2} k_{i 1} & k_{i 2} & 0 & 0 & 0
\end{array}\right]^{T} \\
& C_{j G}=\left[\begin{array}{lllllllll}
0 & 0 & 0 & 0 & 0 & 0 & 0 & 1 & 0
\end{array}\right]
\end{aligned}
$$

\section{REFERENCES}

[1] J. Häfner and B. Jacobson, "Proactive hybrid HVDC breakers - a key innovation for reliable HVDC grids, integrating supergrids and microgrids," in Proc. CIGRE Symposium, Bologna Italy, 2011, pp. B4-B110.

[2] W. Grieshaber, J. P. Dupraz, D. L. Penache, and L. Violleau, "Development and test of a $120 \mathrm{kV}$ direct current circuit breaker," in Proc. CIGRE Paris, 2014.

[3] J. Descloux, B. Raison, and J. B. Curis, "Protection algorithm based on differential voltage measurement for MTDC grids," in Proc. Developments in Power Syst. Protection IET 2014, pp. 1-5.

[4] J. Sneath and A. D. Rajapakse, "Fault Detection and Interruption in an Earthed HVDC Grid using ROCOV and Hybrid DC Breakers," IEEE Trans. Power Del., vol. PP, pp. 1-1, 2014.

[5] K. De Kerf, K. Srivastava, M. Reza, D. Bekaert, S. Cole, D. Van Hertem, and R. Belmans, "Wavelet-based protection strategy for DC faults in multi-terminal VSC HVDC systems," IET Gener. Transm. Distrib. , vol. 5, pp. 496-503, 2011.

[6] L. Xu and L. Yao, "DC voltage control and power dispatch of a multi-terminal HVDC system for integrating large offshore wind farms," IET Renew. Power Gener. , vol. 5, pp. 223-233, 2011.

[7] J. Beerten, S. Cole, and R. Belmans, "Modeling of Multi-Terminal VSC HVDC Systems With Distributed DC Voltage Control," IEEE Trans. Power Syst., vol. 29, pp. 34-42, 2014.

[8] L. Jun, J. Tianjun, O. Gomis-Bellmunt, J. Ekanayake, and N. Jenkins, "Operation and Control of Multiterminal HVDC Transmission for Offshore Wind Farms," IEEE Trans. Power Del., vol. 26, pp. 2596-2604, 2011.

[9] G. O. Kalcon, G. P. Adam, O. Anaya-Lara, S. Lo, and K. Uhlen, "Small-Signal Stability Analysis of Multi-Terminal VSC-Based DC Transmission Systems," IEEE Trans. Power Syst., vol. 27, pp. 1818-1830, 2012.

[10] W. Wang, A. Beddard, M. Barnes, and O. Marjanovic, "Analysis of Active Power Control for VSC-HVDC," IEEE Trans. Power Del., vol. 29, pp. 1978-1988, 2014.

[11] H. Saad, S. Dennetiere, J. Mahseredjian, P. Delarue, X. Guillaud, J. Peralta, and S. Nguefeu, "Modular Multilevel Converter Models for Electromagnetic Transients," IEEE Trans. Power Del., vol. 29, pp. 1481-1489, 2013.

[12] T. M. Haileselassie, "Control, Dynamics and Operation of Multiterminal VSC-HVDC Transmission Systems," Ph.D. Thesis, Norwegian Univ. Sci. Technol., 2012.

[13] J. Z. Zhou, D. Hui, F. Shengtao, Z. Yi, and A. M. Gole, "Impact of Short-Circuit Ratio and Phase-Locked-Loop Parameters on the Small-Signal Behavior of a VSC-HVDC Converter," IEEE Trans. Power Del., vol. 29, pp. 2287-2296, 2014.

[14] C. Dierckxsens, K. Srivastava, M. Reza, S. Cole, J. Beerten, and R. Belmans, "A distributed DC voltage control method for VSC MTDC systems," Elect. Power Syst. Res., vol. 82, pp. 54-58, 2012.

[15] B. Jacobson, P. Karlsson, G. Asplund, L. Harnefors, and T. Jonsson, "VSC-HVDC transmission with cascaded two-level converters," in Proc. CIGRE session, 2010, pp. B4-B110.

[16] S. Skogestad and I. Postlethwaite, Multivariable feedback control : analysis and design, 2nd ed. Chichester: Wiley, 2005.

[17] E. Z. Zhou, O. P. Malik, and G. S. Hope, "Theory and method for selection of power system stabilizer location," IEEE Trans. on Energy Conversion, vol. 6, pp. 170-176, 1991.

[18] Y. Y. Hsu and C. L. Chen, "Identification of optimum location for stabiliser applications using participation factors," IEE Proc. Gener. Transm. Distrib., vol. 134, pp. 238-244, 1987.

[19] P. Kundur, N. J. Balu, and M. G. Lauby, Power system stability and control. New York; London: McGraw-Hill, 1994.

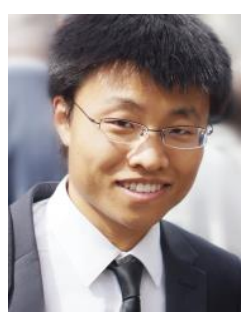

Wenyuan Wang received the B.Eng. degree in electrical and electronic engineering in 2011, from The University of Manchester, Manchester, U.K., where he is currently pursuing the Ph.D. degree. His research interests include operation, stability and control of multi-terminal VSC-HVDC systems.

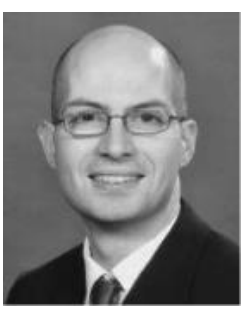

Mike Barnes (M'96-SM'07) received the B.Eng. and Ph.D. degrees from the University of Warwick, Coventry, U.K. In 1997, he was a Lecturer with the University of Manchester Institute of Science and Technology (UMIST, now merged with The University of Manchester), Manchester, U.K., where he is currently a Professor. His research interests cover the field of power-electronics-enabled power systems.

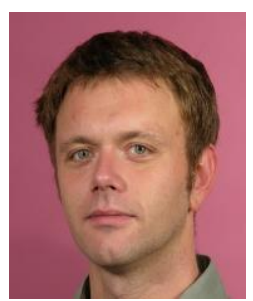

Ognjen Marjanovic (M'08) received the First Class honors degree from the Department of Electrical and Electronic Engineering, Victoria University of Manchester, Manchester, U.K., and the Ph.D. degree from the School of Engineering, Victoria University of Manchester. Currently he is a Senior Lecturer in the School of Electrical and Electronic Engineering at The University of Manchester, UK.

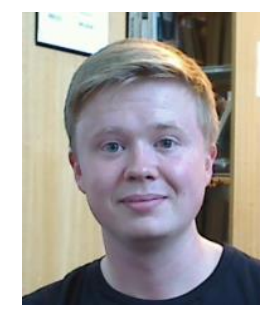

Oliver Cwikowski is a Ph.D. Student at the University of Manchester. He received his MEng degree in 2012 from the University of Manchester. His main research focus is HVDC circuit breakers for application in VSC based grids, which is sponsored by National Grid. His work looks into the design and construction of prototype HVDC circuit breakers, with the aim to aid in the development of a standard for HVDC circuit breakers. 